\title{
Ciudadanía y Transformación Social
}

\author{
Autora: Sonia María Peña Guzmán \\ Universidad Latinoamericana y del Caribe, ULAC \\ profesorasonia12@gmail.com \\ Caracas, Venezuela \\ https://orcid.org/0000-0002-9587-3714
}

\section{Resumen}

La Ciudadanía desde la edad antigua hasta la contemporánea ha presentado una transformación de significado dentro de la sociedad, reflejado en el desarrollo del hombre como ser social y su comportamiento para el cambio. Este ensayo ofrece de manera resumida un avance histórico a fin de realizar una descripción de los avances sociales con la incorporación paulatina de los derechos del individuo influenciados por la religión, de tal manera que la expresión de la ciudadanía ha logrado cierta transformación social con esta influencia religiosa, en la cual, el ciudadano era aquel que además de cumplir con las obligaciones antes descritas debía cumplir con las leyes de Dios. Es así, como se relaciona la ciudadanía con la convivencia y el cristianismo. Tomando como referencia lo antes expuesto y el avance de la historia enmarcada en el ámbito tecnológico, la transformación de la ciudadanía ya para la época del modernismo actual surge la democracia como forma de considerar al ciudadano un ser rodeado de derechos políticos de participación, todo ello, a su vez, enmarcado dentro de los diferentes modelos de ciudadanía que van tejiendo características propias dependiendo del ámbito social de desarrollo.

Palabras clave: ciudadanía; transformación social; sociedad.

Fecha de Recepción: 02-03-2019
Fecha de Aceptación: 17-06-2019
Fecha de Publicación: 05-08-2019 


\title{
Citizenship and Social Transformation
}

\begin{abstract}
Citizenship from the old to the contemporary age has presented a transformation of meaning within society, reflected in the development of man as a social being and his behavior for change. This essay offers a summary of a historical breakthrough in order to make a description of social advances with the gradual incorporation of the rights of the individual influenced by religion, in such a way that the expression of citizenship has achieved a certain social transformation with this influence religious, in which the citizen was the one who, in addition to fulfilling the obligations described above, had to comply with the laws of God. This is how the citizenship relates to coexistence and Christianity. Taking as reference the foregoing and the advance of history framed in the technological field, the transformation of citizenship and for the current modernist era arises democracy as a way to consider the citizen a being surrounded by political rights of participation, all this, in turn, framed within the different models of citizenship that are weaving their own characteristics depending on the social scope of development.
\end{abstract}

Keywords: citizenship; changing society; society.

Date Received: 02-03-2019
Date Acceptance:

17-06-2019
Date Publication:

05-08-2019 


\section{Introducción}

El hombre a través del tiempo ha buscado la manera de lograr una transformación social, para ello ha considerado los cambios económicos, científicos, tecnológicos y sociales, logrando algunos significativos y de avance conllevando al hombre hacia la llamada postmodernidad. Sin embargo, se puede afirmar que no existe una verdadera transformación sino hasta que el hombre logre cambiar el mismo. Este cambio, debe evidenciarse en su forma de ser, hacer y convivir. De ser, cuando él en sí mismo se reconozca como es, acepte lo que es, y determine su esencia como persona y como ciudadano; el hacer, al actuar y estar en concordancia con lo que se dice y con lo que se hace; finalmente, el convivir, como forma de vida en su contexto social.

Considerando lo señalado, la ciudadanía toma relevancia en esta temática a tratar, por cuanto mira el desarrollo del hombre como ser social a través de la historia, por lo que se evidencia la propia transformación social que ha evolucionado desde sus orígenes hasta la presente, y hacia dónde apunta el aprendizaje ciudadano para una mejor transformación comunitaria y social.

Bajo este contexto, el presente ensayo busca desarrollar tanto aspectos históricos de la Edad Antigua (Siglo MMM al IV a.C.), la Edad Media (Siglo V al XIV), la Edad Moderna (Siglo XVI al XVIII), y la edad contemporánea (Siglo XIX, hasta nuestros días), como conceptuales de la ciudadanía; y así establecer reflexiones sobre el logro de la transformación social a la luz de la realidad conflictiva y emergente que vive la sociedad actual.

\section{La Construcción Histórica de la Ciudadanía para la Transformación Social.}

La Edad Antigua (Siglo MMM al TV a.C.), se caracteriza por el inicio de la escritura, sin embargo, la concepción de la ciudadanía de acuerdo a la tradición griega, se puede decir que fue selectiva, Licurgo, formalizó el papel 
de ciudadanos privilegiados a aquellas personas que estaban consciente de sus derechos como lo son la realización del servicio militar y la participación dentro del gobierno, por lo que disfrutaban de las diversas reformas socioeconómicas.

En el caso de Roma, coincidió con los griegos, en la obligación del servicio militar, pero además este nombramiento conllevaba una serie de derechos y obligaciones como el derecho a votar, aunque esta condición y pagar impuestos para alcanzar la virtud cívica o virtus que presentaba similitudes con el concepto de areté en Grecia.

Desde la visión política, se manifiesta una relación ciudad-estado, caracterizada por un espacio demográfico reducido que permite el reconocimiento de cada habitante, suficiencia económica y la independencia política representada por sus propias leyes, donde se establecía que el derecho a la ciudadanía que se adquirían en el nacimiento, con la accesibilidad a la educación, obligaciones militares, participación en las fiestas y prácticas religiosas, variando en esencia dependiendo del Estado al que pertenecía.

Tras la llegada de la Edad Media (Siglo $V$ al XIV), se inicia un crecimiento de la ciudadanía a partir del liderazgo de la Iglesia Católica, sin embargo, surge una dualidad en la ciudadanía, la vista desde la creencia hacia Dios y hacia la oración, frente a la ciudadanía política, con influencia en la burguesía y el comercio. En el orden religioso, se observa la influencia del aspecto espiritual, el ciudadano como ser que asume las orientaciones de Dios, el poder del alma y la creencia de que su salvación depende del comportamiento que éste tenga.

Desde el punto de vista político, en esta época se observa un avance hacia la transformación social, en virtud que la ciudadanía fue buscando significado en el entorno político, aunque discriminándose en forma general con una clasificación social la distinción entre ciudadanos entre los del entorno rural y ciudadanos del entorno urbano, la primera clasificación, se encuentra 
en presencia de la mayor distribución geográfica, por su misma condición social, aunque se consideraban ciudadanos, no gozaban de los mismos derechos de los habitantes de las urbes; la segunda, se desarrolló en las grandes ciudades conformadas ya a finales de la Edad Media, caracterizada por las concentraciones en las urbes o polis y jerarquización social, donde los habitantes gozaban de derechos políticos, económicos y sociales dependiendo de su inclusión en la escala de la sociedad.

En avance de la historia y por ende, de las características particulares de la sociedad y avances tecnológicos y científicos, surge la Edad Moderna (Siglo XVI al XVIII), con tendencias humanísticas y bajo el pensamiento de Leonardo Bruni, que abrió las puertas a un pensamiento de corte renacentista en la obtención de mejoras políticas a través de la participación ciudadana y Nicolás Maquiavelo, exponente de las debilidades presentes en los grupos sociales del momento, donde el predominio de la violencia y la corrupción se apoderaba de las ciudades. En este periodo de la historia, surge la democracia como forma de considerar al ciudadano un ser rodeado de derechos políticos de participación.

Por su parte, Delgado (2017), hace referencia que:

... desde el siglo XVII en la ilustración y, especialmente, XVIII, los derechos entran en la conceptualización de la ciudadanía. Los principios de derecho natural y la justicia natural llevan a una concepción del poder político que comienza con Vitoria y se moderniza con autores como Hobbes, Locke o Rousseau en el llamado contractualismo social (pág. 250).

La llamada Edad Moderna, presenta como características, (a) como aprovechamiento de la ciencia y la tecnología se centra en la concepción antropocéntrica, es decir, se centra en la vida y la felicidad del hombre; (b) el desarrollo de la personalidad a través del arte y la formación literaria, lo que la hace individualista; (c) encumbramiento de las monarquías absolutas, como consecuencia de la inestabilidad económica y problemas sociales de la época; 
y (d) desarrollo de las artes, las ciencias y la literatura.

En el marco de la ciudadanía en la Edad Contemporánea (Siglo XIX, hasta nuestros días), esta época se caracteriza por: (a) la valorización de la ciencia y el método científico; (b) consolidación del sistema capitalista occidental; (c) disputa entre las potencias; y (d) clasificación de los países en desarrollados y subdesarrollados. Estos elementos introducen al hombre en la acción participativa de la sociedad, donde el ciudadano inicia la consolidación de ser independiente pero responsable sobre los sucesos históricos, políticos, culturales e ideológicos que se presentan en la modernidad.

Desde el punto de vista político, la ciudadanía en la Edad Contemporánea, se convirtió en un proceso aún más complejo, en la medida que las personas se insertaban al ámbito de los propios derechos políticos, aunque esta situación varió de una sociedad a otra, por ejemplo,

Desde el aspecto de la pertenencia, en esta etapa, la ciudadanía busco que el hombre que el hombre asumiera la pertenencia de su nación, en países como los Estados Unidos, Francia, la Gran Bretaña y Alemania, la ciudadanía se relacionaba directamente con la nacionalidad, por lo tanto, se da una relación entre la ciudadanía y la nación.

Sin embargo, en la contemporaneidad, la relación entre ciudadanía y nación, se ha manifestado complicada, siendo el caso que, la ciudadanía se presenta a juicio de esta autora, como una manera de reclamo y posesión de los derechos tanto civiles como políticos de los cuales el Estado está en la obligación de satisfacer en función a las necesidades del colectivo, lo que lleva a lo que Smith (2002), citado por Jaramillo (2014), refiere a: “... un proceso de construcción social..." (pág. 170), por supuesto para el surgimiento de lo que dicho autor refiere como nacionalismo. Por lo tanto, la complejidad se encuentra en considerar lo que los ciudadanos creen pensar lo que es conveniente para ellos, y lo que el Estado desde sus posibilidades está en la obligación de cumplir para la satisfacción del colectivo en cuanto a los 
derechos sociales, políticos y civiles.

\section{La Construcción Conceptual de la Ciudadanía}

Las diversas concepciones de la ciudadanía, circundan sobre los derechos y obligaciones del hombre como ser dentro de la sociedad. Asimismo, se observarán algunas definiciones de ciudadanía a objeto de caracterizar su evolución conceptual.

En primer lugar, Marshall y Bottomore (1998), refieren que: "es aquel estatus que se concede a los miembros de pleno derecho de una comunidad. Sus beneficiarios son iguales en cuanto a los derechos y las obligaciones que implica" (pág. 37), estos autores asumen la postura de la posesión de los derechos civiles y políticos en una relación de igualdad, pero también de reciprocidad en cuanto a que a la presencia de derechos se encuentran las obligaciones como ciudadano.

En segundo lugar, Duchastel (2002), señala que:

... es un proceso de institucionalización del lazo entre el individuo y la sociedad política que se caracteriza por dos movimientos: uno de extensión, que implica la adquisición progresiva de la misma por el conjunto de los miembros de una sociedad política, y otro de comprensión, que refiere a la tendencia a multiplicar sus dimensiones (pág. 15).

La ciudadanía entonces ha sido vista como un sistema de derechos, a la salud, a la educación, al bienestar en general, como compromiso del Estado hacia el ciudadano, pero también ha sido visto, como la forma del comportamiento humano frente a la sociedad en respuesta a su compromiso hacia los derechos que asume como ciudadano.

Estas dos maneras de mirar la ciudadanía, han llevado a la configuración de modelos de ciudadanía, entre los cuales se pueden considerar los de Anchustegui (2011a), resumiendo su propuesta de “...clasificación en: (a) la comunidad liberal y los derechos y libertades 
individuales; (b) la sociedad comunitarista y la lealtad nacional; (c) modelo republicano y la virtud cívica" (pág. 13-20).

Modelo de la comunidad liberal y los derechos y libertades

individuales: Este modelo hace referencia a la construcción de los derechos individuales sobre la entereza del Estado, es el ciudadano quien a partir de su noción de libertad e igualdad maximiza su liderazgo por encima de la doctrina del Estado. A este respecto, Anchustegui (2011b), plantea que:

El contenido de los derechos desde la perspectiva liberal se resume, pues, en las nociones de propiedad, libertad e igualdad, entendidas y conjugadas de diversos modos por las diversas variantes del pensamiento liberal. Con todo, la preocupación del liberal respecto a la política es, más que la cuestión de quién tiene el poder, cómo evitar que los derechos y libertades del individuo sean limitados o anulados por los demás, y en especial por el Estado (pág. 13).

El modelo liberal, plantea tres aspectos, a saber, como son el individuo liberal, la comunidad liberal y la ética liberal, el primero referido al ciudadano común, consumidor de los bienes de servicio, por tal motivo, se convierte en un cumplidor de las responsabilidades y leyes que esto acarrea; el segundo, prevalece la justicia del contexto donde se desenvuelve el individuo en comunidad; y finalmente, la tercera, la ética garantiza los deberes y derechos de los individuos, por lo tanto tiene un valor moral.

Modelo de la sociedad comunitarista y la lealtad nacional: por su parte, Anchustegui (2011c), especifica que:

Se entiende que la comunidad política está al servicio de la identidad comunal. Aquí, el sujeto político principal no es el individuo, sino la comunidad, una comunidad considerada natural o como comunidad de pertenencia. Se enfatiza el grupo cultural o étnico, la solidaridad entre quienes comparten una historia o tradición (pág. 14). 
Modelo republicano y la virtud cívica: En palabras de Anchustegui (2011d), se refiere a que este modelo: “...puede entenderse como una expresión de la identidad cívica. Es decir, como aquella concepción de la vida política que preconiza un orden democrático dependiente de la vigencia de la responsabilidad pública de la ciudadanía" (pág. 18).

Además de los modelos antes señalados, se encontraron otros, los cuales se interpretaron por la autora de la siguiente manera:

1. Modelo de sociedad civil: como máximo exponente se ubica al filósofo Michael Walzer. Este modelo consiste en asociaciones voluntarias como sociedades civiles, cooperativas, sindicatos, partidos, movimientos sociales, entre otros dirigidos al ejercicio de la ciudadanía y la búsqueda del bien común.

2. Modelo comunitarista: entre los que defienden esta postura, se encuentran los filósofos Michael Sandel, Charles Taylor, Michael Walzer y Alasdair MacIntyre. Este modelo es de origen norteamericano, progresista, responsable, donde se manifiesta un vínculo entre la persona y la identidad de la comunidad a la que pertenece.

3. Modelo de democracia deliberativa: como principal representante Jürgen Habermas. Este modelo se inclina hacia que el único medio de llegar a consensos y soluciones a problemáticas públicas es el diálogo, la tolerancia la reflexión. Está presente en este modelo la manifestación del espacio público como máxima para el logro de la participación, el poder comunicativo como medio para el aporte de ideas y soluciones.

4. Modelo de capital social: el capital social representa las organizaciones sociales, culturales, políticas, comunitarias, entre otras que interactúan y pueden entre sus potencialidades tener provecho mutuo en la resolución de las problemáticas que puedan afectar a la sociedad en general.

5. Modelo de política ciudadana: constituye una manera de 
participación ciudadana, propone que el ciudadano se convierta en un agente activo de las decisiones públicas, y ayude a resolver problemas públicos en su ambiente inmediato. Este modelo se muestra bajo cuatro maneras: (a) participación ciudadana; (b) participación política; (c) participación comunitaria; y (d) participación social:

La primera, participación ciudadana, es el derecho del ciudadano en participar en los asuntos públicos para el desarrollo e impulso locas; el segundo; participación política, es el derecho del ciudadano a ser arte y parte de la gestión de gobierno, se incluye aquí, su propio derecho a proponerse como representante, el derecho al voto, a realizar actividades comunitarias, actividades de protesta, actividades de iniciativa propia, entre otras.

La tercera, participación comunitaria, consiste en un trabajo colectivo y voluntario, donde se participa activamente con responsabilidad y compromiso dentro del contexto social donde se desenvuelve; y por última, la cuarta, participación social, se inserta en la participación tanto dentro del propio contexto social como fuera de él, y se caracteriza por: valoración del colectivo, aprovechamiento de los recursos, aprendizaje y educación social, apoyo y respaldo a iniciativas, dedicación de tiempo, compromiso, entre otras.

6. Modelo de democracia radical: como representantes se tienen a las filósofas Adela Cortina y Chantal Mouffe. Con respecto a este modelo, Cortina (1994), citada por Serna (2008a), plantea una democracia radical presentada originalmente por Habermas, propia de una izquierda socialista no comunista, para la cual define como una democracia:

... participativa, en la que los ciudadanos ejercen su autonomía en solidaridad, con lo cual habríamos hallado en esta propuesta el modelo de procedimiento socialista buscado porque además de pretender ser aplicado al caso de sociedades complejas y no ya a la polis griega o a comunidades cuya unidad de objetivos hoy trataríamos de recrear. Tal idea de participación viene abonada por dos de las dimensiones del enfoque habermasiano: la ética discursiva y la teoría de la sociedad 
(pág. 931).

Por su parte, Mouffe (1999), citada por Serna (2008b): propone el “... agonismo, interpretado como una lucha de personas oponentes, adversarios, pero que no se pueden considerar enemigos, sino con diferencias de pensamiento, lo que abre la posibilidad del pluralismo, elemento fundamental para el desarrollo de mayores niveles de democracia" (pág. 275-276).

Puede entenderse entonces que, aunque son modelos independientes, pueden relacionarse, cada uno posee sus propias particularidades, el centro de interés es el hombre, es decir, se manifiesta humanista, con la búsqueda de la integración y beneficios para él, tanto individual como en colectivo. En este sentido, la historia y los modelos de ciudadanía han estado rodeados de hechos que conllevan a mejorar al hombre como ser humano, y esto supone mejorar su entorno y calidad de vida.

\section{La Ciudadanía para la Transformación}

A lo largo de la historia la concepción de ciudadanía ha variado en importancia y significado político y social, donde se han planteado diversos modelos, dando relevancia a la participación del hombre en la vida democrática. Sin embargo, la ciudadanía es vista como la inserción al hombre en la sociedad, ser ciudadano implica más allá del derecho al voto y la participación, poseer valores que permitan la reconstrucción de una sociedad que a lo largo del tiempo se ha visto afectada por acciones propias del individuo que alejan la tolerancia, el respeto hacia el otro y al entorno.

Ahora bien, partiendo de esta premisa, la transformación de la sociedad solo se logra cuando realmente el hombre se convierta en un ciudadano de ética personal y social, la primera en la consideración de los valores primordiales como el respeto, el amor, la convivencia, la vida hacia sí mismo y hacia el otro, la responsabilidad y el compromiso, entre otros; mientras que 
la segunda, realza la vivencia en sociedad, asumiendo los deberes y ejerciendo sus derechos.

\section{Conclusiones}

Desarrollado los aspectos anteriores, se puede concluir en los siguientes aspectos:

1. La historia ha estado rodeada de situaciones que llevan a mejorar la calidad de vida del hombre en todas sus dimensiones, económico, social y personal, esta última es fundamental para el logro de las anteriores, ya que solo con el crecimiento del hombre como hombre es como puede mejorar su entorno.

2. La ciudadanía es la concepción dada desde el punto de vista epistemológico y axiológico a la acción del hombre en un contexto social, en el cual se hacen presentes los derechos y deberes tanto del individuo como de la colectividad, inmersa en ella, la adquisición progresiva de la conformación de una sociedad política en respuesta al compromiso como ciudadano.

3. La construcción de la ciudadanía se manifiesta de diversas maneras, de acuerdo al modelo asumido, entre ellos se encuentran: (a) Modelo de la Comunidad Liberal y los Derechos y Libertades Individuales; (b) Modelo de la Sociedad Comunitarista y la Lealtad Nacional; (c) Modelo Republicano y la Virtud Cívica; (d) Modelo de Sociedad Civil; (e) Modelo Comunitarista; (f) Modelo de Democracia Deliberativa; (g) Modelo de Capital Social; y (h) Modelo de Política Ciudadana. Cada uno de ellos con sus características propias, algunos convergen y otros son opuestos, pero su objetivo final, es la incorporación de los derechos y deberes para hacer una ciudadanía hacia la sociedad.

4. La transformación social apunta hacia la formación del individuo desde la juventud, a fin de asumir la responsabilidad y compromiso de una 
sociedad cónsona con el respeto hacia las normativas, cumplimiento de sus deberes y respeto de los derechos hacia sí mismo y el colectivo.

\section{Referencias}

Anchustegui, E. (2011a,b,c,d). Derechos Humanos y Modelo de Ciudadanía. Límite: Revista Interdisciplinaria de Filosofía y Psicología, 6(24), 9-28, e-ISSN: 0718-1361. Recuperado de:

http://www.redalyc.org/articulo.oa?id=83622474002

Delgado, E. (2017). Hacia una (Re) conceptualización de la Democracia Contemporánea. ISBN: 978-84-946316-5-8. Sevilla, España: Fénix Editora.

Duchastel, J. (2002). La Ciudadanía en las Sociedades Contemporáneas: Entre Globalización de los Mercados y Reivindicaciones Democráticas. Oñati, Espagne: Texte présenté au Workshop Ciudadanía y costos sociales: los nuevos marcos de regulación, Organisé par l'Institut international de sociologie juridique. Recuperado de: http://www.ieim.uqam.ca/IMG/pdf/duchastel-mai-2002-onati.pdf Jaramillo, R. (2014). Ciudadanía, Identidad Nacional y Estado-Nación. Revista Lasallista de Investigación, 11(2), 168-180, e-ISSN: 1794-4449. Recuperado de: http://www.redalyc.org/pdf/695/69539788019.pdf Marshall, T. \& Bottomore, T. (1998). Ciudadanía y Clase social. Madrid, España: Alianza Editorial.

Serna, P. (2008a,b). Democracia Radical y Ciudadanía. Eidos, (9), 272-280, e-ISSN: 1692-8857. Recuperado de:

http://www.scielo.org.co/scielo.php?script=sci abstract\&pid=S1692$\underline{88572008000200011 \& \operatorname{lng}=\text { en\&nrm=iso }}$ 


\section{Sonia María Peña Guzmán}

e-mail: profesorasonia12@gmail.com

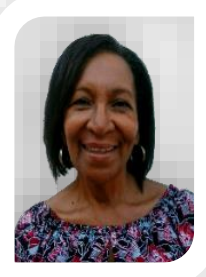

Nacida en Falcón, Venezuela, el 2 de junio del año 1954. Profesora de Castellano, egresada de la Universidad Pedagógica Experimental Libertador "Rafael Alberto Escobar Lara"; Especialista en Planificación y Evaluación de la Educación, Universidad Santa María; Magister Scientiarum en Educación Superior, Universidad Nacional experimental de la Fuerza Armada Nacional Bolivariana (UNEFA); Doctorante en Ciencias de la educación, Universidad Latinoamericana y del Caribe (ULAC), Caracas, Venezuela; Profesora de postgrado UNEFA, Miranda, Venezuela; Coordinadora de la carrera Maestría en Educación Superior, UNEFA; Profesora jubilada en el área de Castellano. Directora en ejercicio de la Unidad Educativa Estadal "Dolores González".

El contenido de este manuscrito se difunde bajo una Licencia de Creative Commons ReconocimientoNoComercial-Compartirlgual 4.0 Internacional 